\title{
Research of High Precision Temperature Controller in Volatile Organic Compounds Separation
}

\author{
Hao Lan ${ }^{1, a^{*}}$, Junming Chen ${ }^{1, b}$, Zhi Cai ${ }^{2, c}$, Rong Deng ${ }^{2, d}$ \\ ${ }^{1}$ College of Polytechnic, Hunan Normal University, Changsha 410008, China \\ ${ }^{2}$ Lihe Technology (Hunan) Co., Ltd. Changsha 410205, China \\ a Nancy050414@126.com, b cjmrise@outlook.com, c caizhi07@163.com, b593437254@qq.com
}

Keywords: Organics, High precision, Temperature control.

Abstract. Temperature control is significant in the process of extraction and separation of organics, whose content is an important indicator of water quality. In this paper, a high precision temperature controller is designed. PT100 is applied in temperature detection, REF200, a constant current source, and LTC6800, a high precision AD conversion, are applied in signal processing circuit, improved PID algorithm is applied in temperature control, TM4C1233H6PM is applied as the core of control. The experimental results show that the temperature controller has good control effect in temperature control including linear temperature increasing process and step temperature increasing process, the sampling precision is $\pm 0.03^{\circ} \mathrm{C}$ and control precision is $\pm 0.2^{\circ} \mathrm{C}$.

\section{Introduction}

Environmental protection is a China's basic state policy, it is not only a development issue, but also a people's livelihood issue, since the Sixteenth Congress, China has put environmental protection as a major strategic which benefits both the present and future generations.

Pollutants in water environment including inorganics, organics, microorganisms, radioactive materials, etc ${ }^{[1,2]}$. It will consume a large amount of dissolved oxygen, when organics are oxidated by organisms in water. Meanwhile, the nutrients released by the decomposed organics will increase the eutrophication of water environment, which will cause algae explosive growth and greatly reduce water aeration. Finally, the water become black and smelly. The effects of volatile organic compounds on human health are also serious. Only very low concentrations of irritation organic can cause eye, throat and skin discomfort; toxic organics can cause nervous system disorders, liver and kidney dysfunction, respiratory diseases, reproductive system and immune system defects, leukemia and other diseases; many organic compounds are also proved to be carcinogens of a variety of cancers.

There are little difference in their boiling point, as a result, the separation of them is difficult. Temperature control is significant in the process of extraction and separation of organics, the temperature controller must have high precision, stability and repeatability.

\section{Design of temperature controller}

System block diagram of temperature controller.

In this paper, PT100 is applied in temperature sampling; sampled signals are input to AD chip, LTC2472, after voltage follower and amplifying circuit; MCU changes the voltage value into real-time temperature, then controls the temperature through changing the PWM signal calculated by an improved PID control algorithm ${ }^{[3-5]}$, and MCU also sends the temperature to host controller through RS-485 bus. The control process shown in Fig.1: 


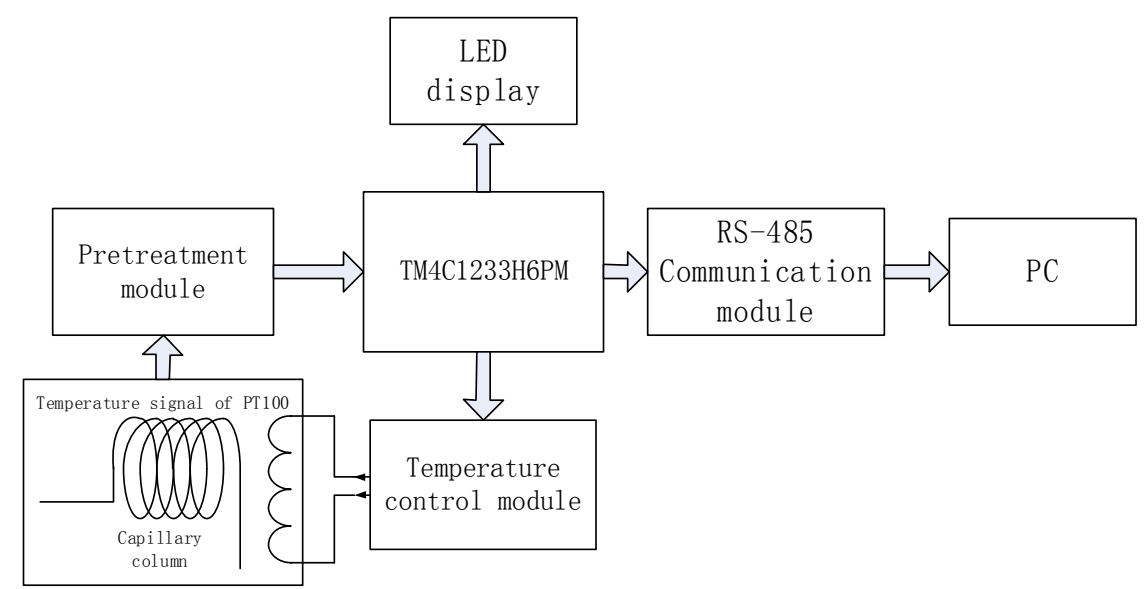

\section{Control algorithm}

Fig.1. Block diagram of linear temperature increasing system

Improved PID control algorithm is applied in temperature control. The output of basic increment PID controller can be expressed as follows:

$e(k)=r(k)-y(k)$

$\Delta \mathrm{u}(\mathrm{k})=\mathrm{K}_{\mathrm{t}}[\mathrm{c}(\mathrm{k})-\mathrm{c}(\mathrm{k}-1)]+\mathrm{K}_{\mathrm{l}} \mathrm{c}(\mathrm{k})+\mathrm{K}_{\mathrm{p}}[\mathrm{c}(\mathrm{k})-2 \mathrm{c}(\mathrm{k}-1)+\mathrm{c}(\mathrm{k}-2)]$

Where: $\quad r(k)$ : aim temperature at the time of $\mathrm{k}$;

$y(k)$ : real temperature at the time of $\mathrm{k}$;

$e(k)$ : the error between real temperature and aim temperature at the time of $\mathrm{k}$;

$\mathrm{u}(\mathrm{k})$ : the output of controller at the time of $\mathrm{k}$;

$\Delta \mathrm{u}(\mathrm{k}): \mathrm{u}(\mathrm{k})-\mathrm{u}(\mathrm{k}-1)$;

$K_{R}, K_{l}, K_{D}$ : parameters of PID controller.

(2) Can be rewritten:

$\Delta n(k)=\left(K_{P}+K_{I}+K_{D}\right) e(k)-\left(K_{P}+2 K_{D}\right) e(k-1)+K_{D} e(k-2)$

Aim temperature is a linear function, when linear temperature increasing, according to the rate. And the temperature control algorithm is designed combining with integral separation PID $\operatorname{algorithm}^{[6-9]}$.

\section{Hardware design of temperature controller}

The temperature sampling module is consist of pretreatment circuit, constant current source circuit, and $\mathrm{AD}$ conversion circuit, as shown in Fig.2:

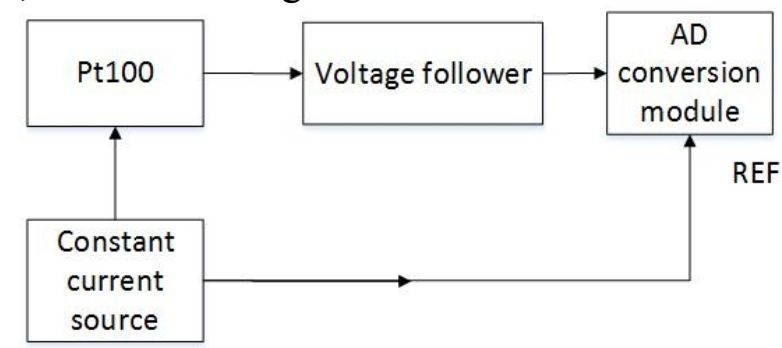

Fig.2. The temperature sampling module.

\section{Design of PT100 temperature sampling module}

The resistance of PT100 at $0^{\circ} \mathrm{C}$ and $100^{\circ} \mathrm{C}$ are respectively $100 \Omega$ and $138.5 \Omega$, the relationship between resistance and temperature follow quadratic function relation ${ }^{[10]}$, as shown in (4).

$$
R(T)=R_{0}\left(1+A T-B T^{2}\right)
$$

Where: $\quad R(T)$ and $R_{0}$ are respectively the resistance at $T^{\circ} \mathrm{C}$ and $0^{\circ} \mathrm{C}$;

$$
\begin{aligned}
& \text { A: } 3.90802 \times 10-3 /{ }^{\circ} \mathrm{C} \text {; } \\
& \text { B: }-5.80195 \times 10-7 /{ }^{\circ} \mathrm{C} \text {. }
\end{aligned}
$$

It is obviously that $R(T)$ is a parabola, instead of a line. A sample method is designed in order to simplify the design with high sampling precision. A reference table of the resistance of PT100 is built, 
finding the interval of detected resistance in the resistance table, then calculating the real-time temperature by linear interpolation:

$$
T x=T 1+(T 2-T 1) \times(R x-R 1) \times(R 2-R 1)
$$

\section{Pretreatment model of temperature signal}

(1) Conditioning circuit

The LTC6800 is a precision instrumentation amplifier. The CMRR is typically $116 \mathrm{~dB}$ with a single $5 \mathrm{~V}$ supply and is independent of gain. The input offset voltage is guaranteed below $100 \mu \mathrm{V}$ with a temperature drift of less than $250 \mathrm{nV} /{ }^{\circ} \mathrm{C}$. The LTC6800 is easy to use; the gain is adjustable with two external resistors, like a traditional op amp. The LTC6800 uses charge balanced sampled data techniques to convert a differential input voltage into a single ended signal that is in turn amplified by a zero-drift operational amplifier. The differential inputs operate from rail-to-rail and the single ended output swings from rail-to-rail. The circuit shown in Fig.3:

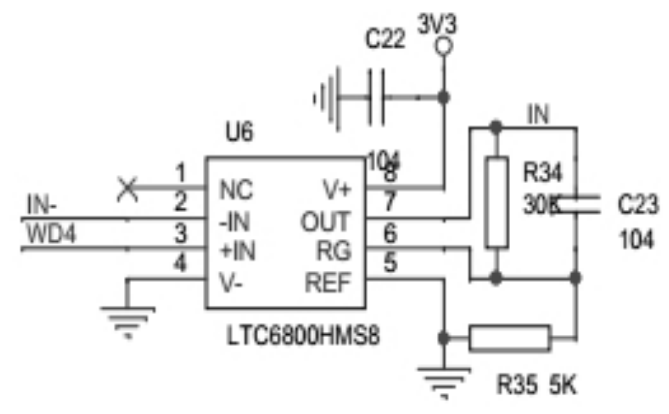

The gain can be calculated:

Fig.3. Voltage follower circuit

$$
G-1+\frac{R_{34}}{R_{35}}-1+\frac{30 k \Omega}{5 k \Omega}-7
$$

(2) Constant current source

REF200 chip is applied in constant current source circuit to provide power to PT100 sensor. There are a 100uA current source and a mirror current source in REF200, one of the sources is applied to provide power to PT100, the other is applied to produce reference voltage to eliminate the unexpected effect of environment changing, as shown in Fig.4:

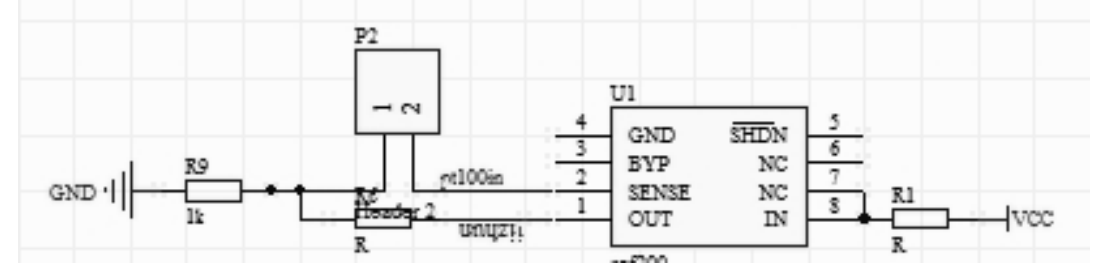

Fig.4. REF200 current source circuit

(3) AD conversion module

LTC2472, a 16 bit high precision and 250sps or $1 \mathrm{ksps}$ conversion speed AD conversion chip, is applied in $\mathrm{AD}$ conversion module. There is a standard $1.25 \mathrm{~V}$ voltage output with $0.1 \%$ initial precision and $2 \mathrm{ppm} /{ }^{\circ} \mathrm{C}$ temperature drift inside LTC2472; it applies specialized sampling strategy, as a result, its average input current is several orders less than traditional $\mathrm{AD}$ conversion chip. And MCU communicates with it through SPI bus.

Pin 1 is $1.25 \mathrm{~V}$ reference voltage output, pin3, 4, 5, 6 are connected with MCU to communication, as shown in Fig.5: 


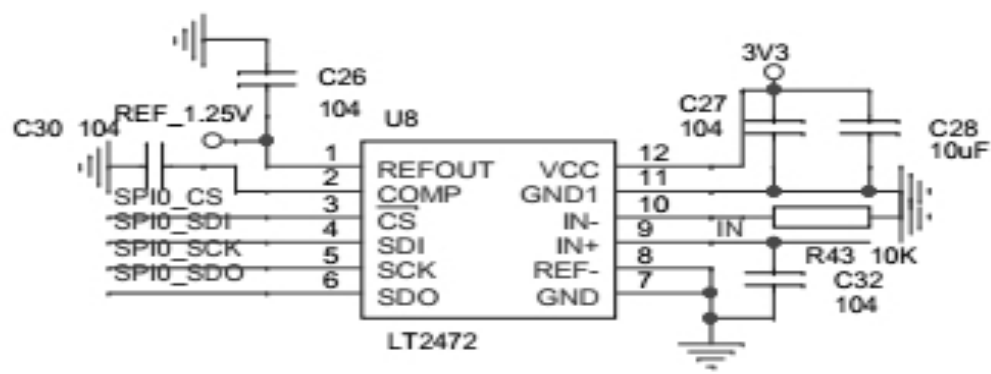

Fig.5. LTC2742 circuit

\section{MCU module}

TM4C1233H6PM is applied as controller chip, it is a 32-bit core from ARM's Cortex-M class MCU, delivering $80 \mathrm{MHz} / 100$ DMIPS, with $\mu$ DMA, general purpose timer module, watchdog timer, sleeping module, GPIO, and 12-bit AD conversion module. The circuit of MCU module shown in Fig.6:

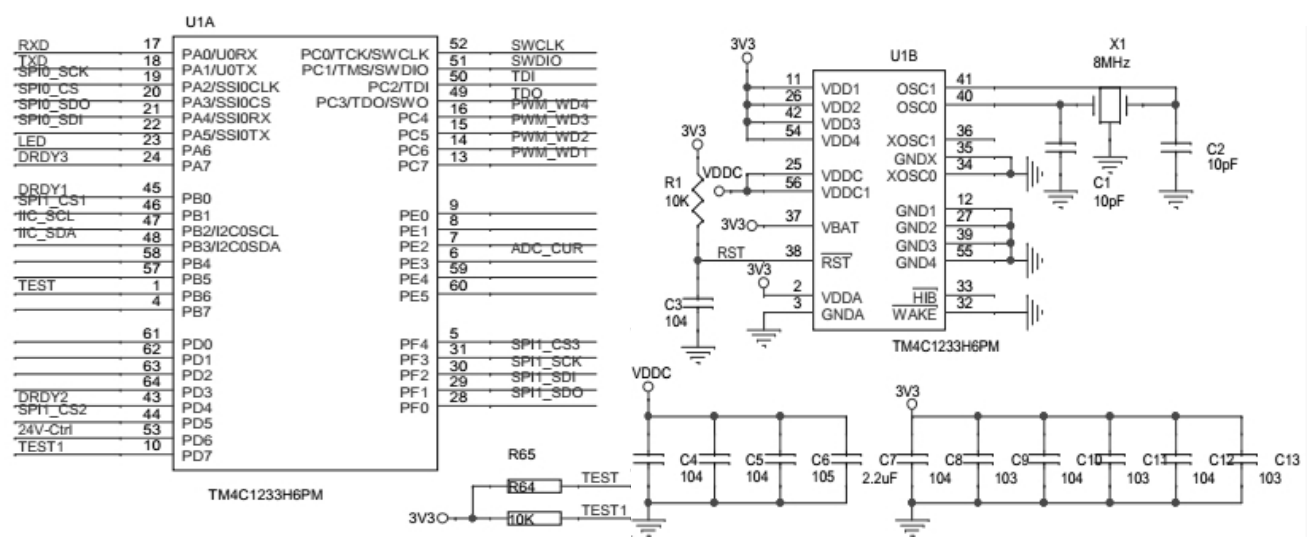

Fig.6. TM4C1233H6PM circuit.

\section{Temperature controller module}

A switch circuit is applied to control the whole heat circuit, there is no power for heat circuit when the switch is off, as shown in Fig.7

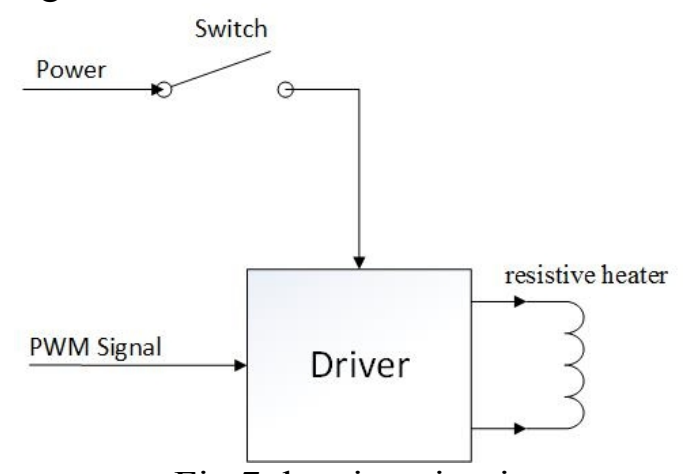

Fig.7. heating circuit

RJK0653DPB, a kind of $\mathrm{N}$ channel enhancement mode MOSFET, is applied as driver for heating device. MOSFET can pass high current, and is widely applied in high current driving circuit; the on-resistance of RJK0653DPB is only $3.8 \mathrm{~m} \Omega$ when the turn-on voltage is $10 \mathrm{~V}$, its switching frequency can reach $10 \mathrm{MHz}$, and the drive voltage can reach $60 \mathrm{~V}$, it can drive 22.5A large current.

The output voltage of MCU pin is 3.3V, it can't drive MOSFET directly, as a result, a triode is applied, resistive heater will heat when the PWM signal is low, and resistive heater won't work when PWM signal is high contrarily. Heating drive circuit shown in Fig.8: 


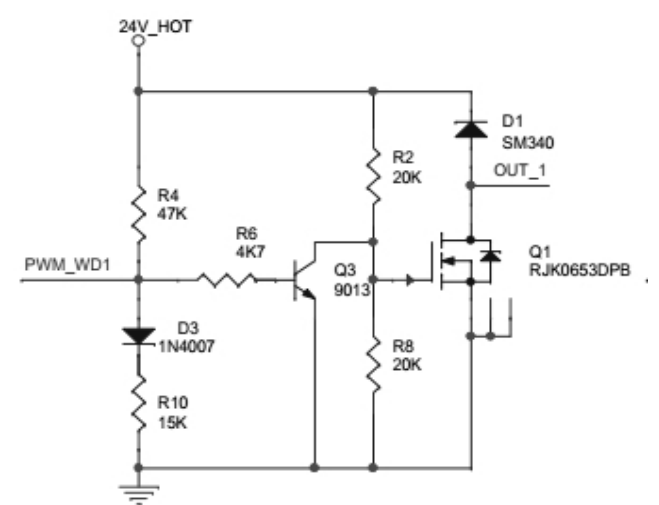

\section{RS-485 Communication module}

Fig.8. Temperature control circuit

Temperature controller communicate with host controller through RS-485 bus. The transmission distance and transmission of RS-485 bus can reach $3000 \mathrm{~m}$ and $10 \mathrm{Mbps}$ respectively. The RS-485 bus can connect 128 transceivers at most with high noise immunity. It is widely applied in industrial control, the circuit of communication module shown in Fig.9:

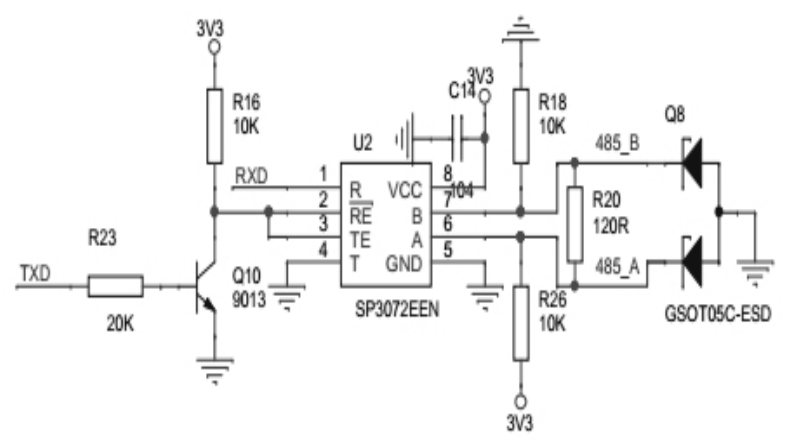

Fig.9. RS-485 communication circuit

\section{Controller diagram and error analysis}

Diagram of liner heating controller system and the experiment facility of error analysis shown in Fig.10:

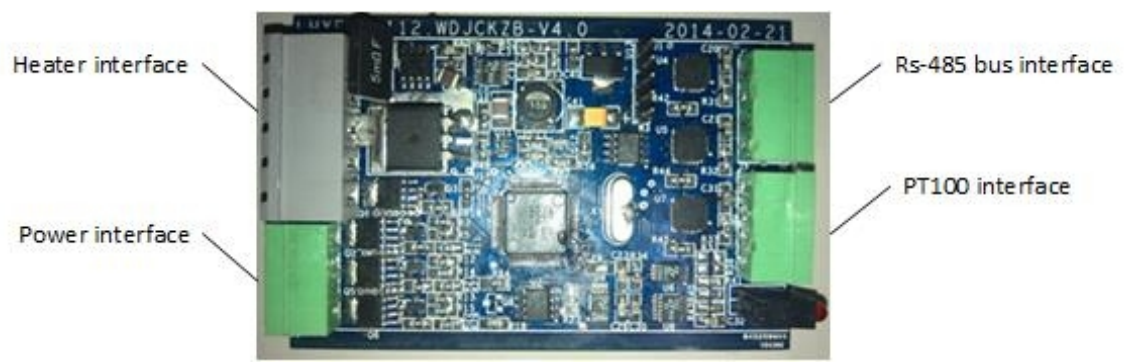

(a) Physical map of temperature controller

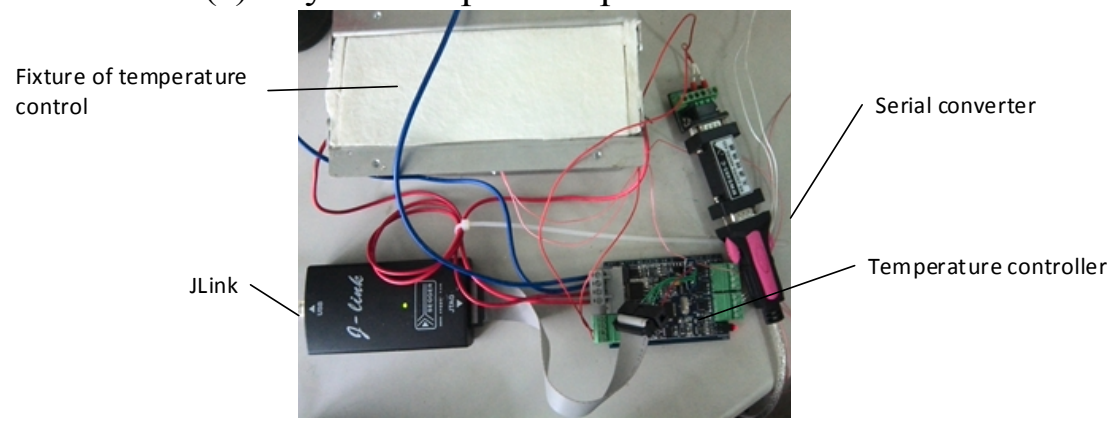

(b) Physical map of experiment system

Fig.10. Physical map of temperature controller and experiment system 
Temperature controller in this paper is test at $0^{\circ} \mathrm{C}$ and $60^{\circ} \mathrm{C}$ environmental temperature three times respectively. In this test, the initial temperature is $65^{\circ} \mathrm{C}$, first step, increasing the temperature up to $100^{\circ} \mathrm{C}$ in four minutes, then maintaining the temperature at $100^{\circ} \mathrm{C}$ for 2 minutes; third step, increasing the temperature up to $140{ }^{\circ} \mathrm{C}$ in 8.5 minutes; finally, maintaining $140{ }^{\circ} \mathrm{C}$ for 310 seconds. The temperature curves at same environmental temperature and different environment temperature are contrasted to analyze the repeatability, and the effects of environmental temperature, shown in Fig.11:

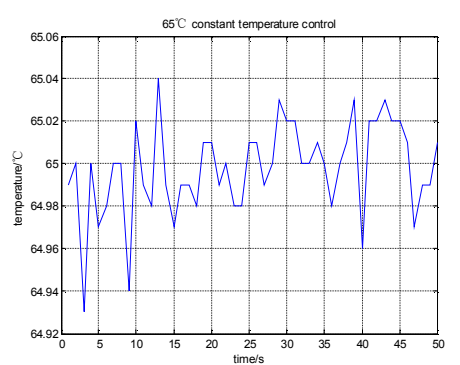

(a) $65^{\circ} \mathrm{C}$

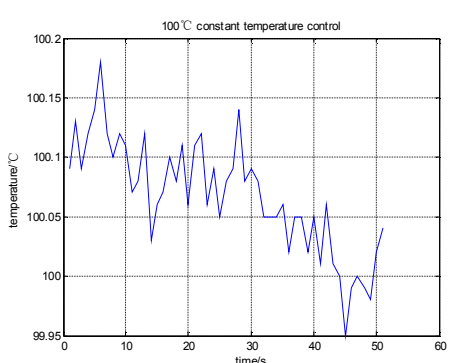

(b) $100^{\circ} \mathrm{C}$

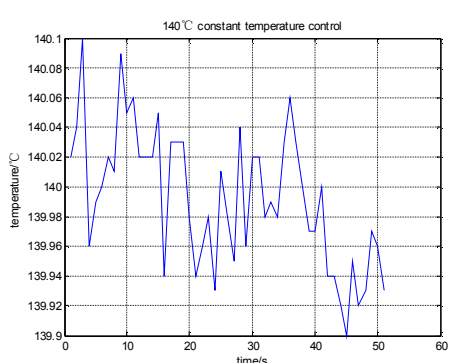

(c) $140^{\circ} \mathrm{C}$

Fig.11. Temperature curve of constant temperature control

Fig. 11 shows the temperature curve of constant temperature control at different environmental temperature, and the properties of constant temperature control shown in Tab.1.

Tab.1. Properties of constant temperature control

\begin{tabular}{cccc}
\hline Temperature $/{ }^{\circ} \mathrm{C}$ & $\mathrm{Max}-\mathrm{Min} /{ }^{\circ} \mathrm{C}$ & $\mathrm{Mean} /{ }^{\circ} \mathrm{C}$ & $\mathrm{STD}$ \\
\hline 65 & 0.11 & 64.9976 & 0.022 \\
100 & 0.23 & 100.0671 & 0.0474 \\
140 & 0.2 & 139.9925 & 0.0461 \\
\hline
\end{tabular}

The temperature curves of step temperature increasing at different environmental temperature shown in Fig.12:

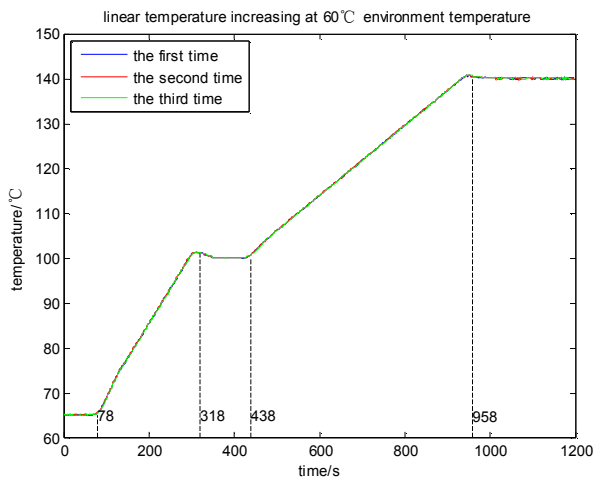

(a)Temperature curve at $0^{\circ} \mathrm{C}$ environment

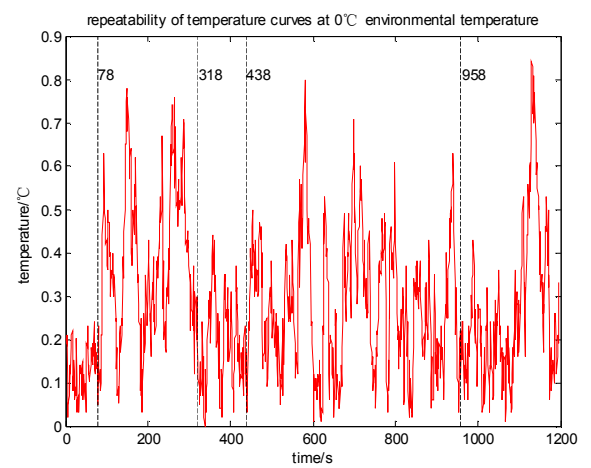

(c) Error at $0^{\circ} \mathrm{C}$ environment

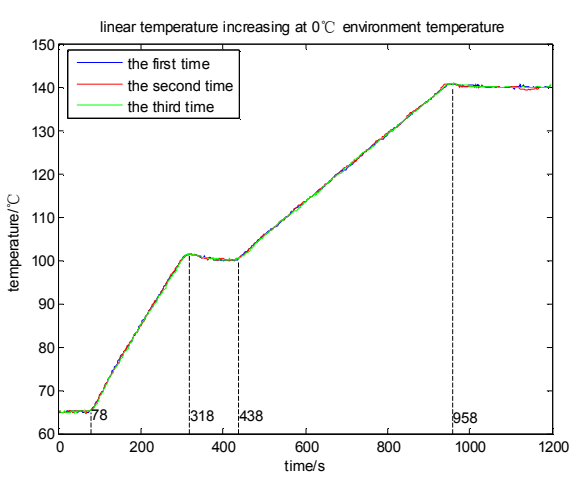

(b)Temperature curve at $60^{\circ} \mathrm{C}$ environment

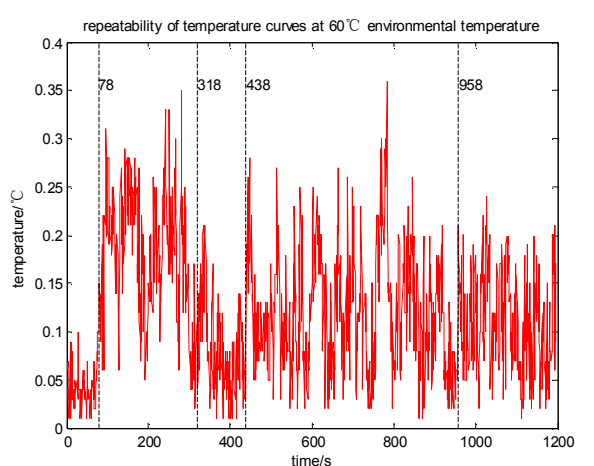

(d) Error at $60^{\circ} \mathrm{C}$ environment

Fig.12. The temperature curves of step temperature increasing. 
It is obvious that the temperature curve at different environmental temperature have high repeatability in step temperature increasing process. The error in temperature increasing process is much more than it in constant temperature control process, and the greater the rate is, the greater the error will be. This phenomenon is caused by the temperature increasing control. the error of constant temperature control is less than $\pm 0.2^{\circ} \mathrm{C}$; the response time of controller is short, and the overshoot is small; the control results is satisfactory in linear temperature increasing and step temperature increasing, shown in Fig.13:

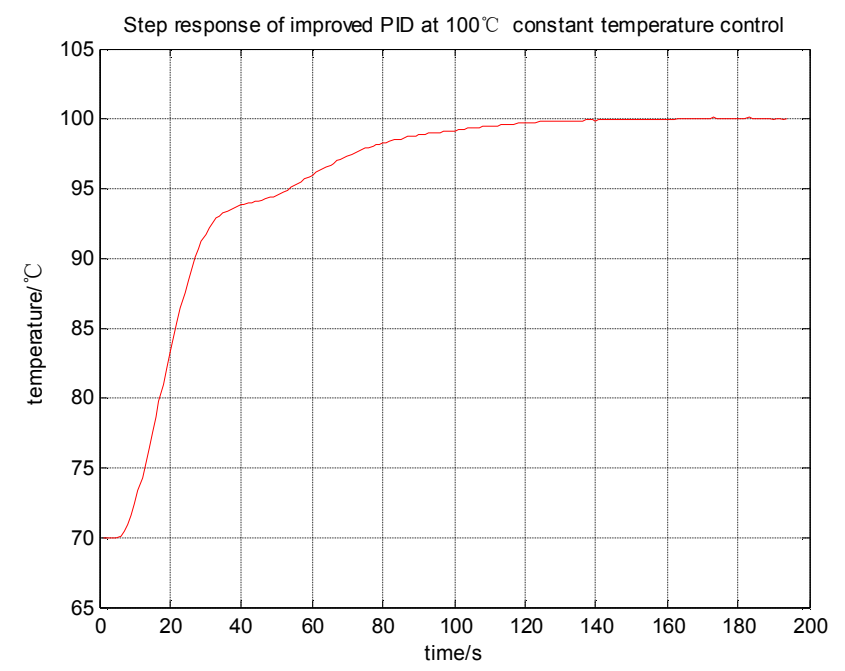

Fig.13. Step response of improved PID.

\section{Conclusion}

The temperature controller is consist of temperature measurement part and temperature control part, PT100 is applied in the temperature measurement part in this paper, the precision of measurement is butter than $0.03^{\circ} \mathrm{C}$, and the range of measurement is $0 \sim 300^{\circ} \mathrm{C}$.Improved PID control is applied, the response time of controller is short, and the overshoot is small, the error of constant temperature control is less than $\pm 0.2^{\circ} \mathrm{C}$, the control results is satisfactory in linear temperature increasing and step temperature increasing, the tracing ability of target temperature can meet the need. Temperature controller communicate with host controller through RS-485 bus, so that temperature controller can send the real-time temperature data to host controller, and host controller can send the target curve of temperature increasing to temperature controller.

\section{Acknowledgements}

The authors would like to appreciate Changsha Municipal Science and Technology Commission (k1403141-11).

\section{References}

[1] Lian-Jun Bao, Keith A. Maruya, Shane A. Snyder, Eddy Y. Zeng. China's water pollution by persistent organic pollutants[J]. Environmental Pollution, 2012, 163:100-108.

[2] Linghua Liu, Huaidong Zhou. Investigation and assessment of volatile organic compounds in water sources in China[J]. Environmental Monitoring and Assessment, 2011, 173(1-4):825-836.

[3] Grassi E, Tsakalis K. PID controller tuning by frequency loop-shaping: application to diffusion furnace temperature control[J]. IEEE Transactions on Control Systems Technology, 2000, 8(5): 842-847. 
[4] Frank David, Karine Jacq, Pat Sandra, Andrew Baker, Matthew S. Klee. Analysis of potential genotoxic impurities in pharmaceuticals by two-dimensional gas chromatography with Deans switching and independent column temperature control using a low-thermal-mass oven module[J]. Analytical and Bioanalytical Chemistry, 2010, 396(3): 1291-1300.

[5] V. A. Vlezko, A. E. Kokh. A Distributed Temperature-Control System for a Single-Crystal Growth Apparatus[J]. Instruments and Experimental Techniques, 2004, 47(4): 562-566.

[6] C. Deng, S. Q. Xie, J. Wu, X. Y. Shao. Position error compensation of semi-closed loop servo system using support vector regression and fuzzy PID control[J]. The International Journal of Advanced Manufacturing Technology, 2014, 71(5-8):887-898.

[7] Dinh Quang Truong, Truong Quoc Thanh, Kyoung Kwan Ahn. Development of a novel linear magnetic actuator with trajectory control based on an online tuning fuzzy PID controller[J]. International Journal of Precision Engineering and Manufacturing, 2012, 13(8):1403-1411.

[8] Yang Yi, Hong Shen, Lei Guo. Statistic PID tracking control for non-Gaussian stochastic systems based on T-S fuzzy model[J]. International Journal of Automation and Computing, 2009, 6(1):81-87.

[9]Biao Yang, Guian Liang,. Self-adaptive PID controller of microwave drying rotary device tuning on-line by genetic algorithms[J]. Journal of Central South University, 2013, 10:2685-2692.

[10] V. Žužek, V. Batagelj. Determination of PRT Hysteresis in the Temperature Range from $-50{ }^{\circ} \mathrm{C}$ to $300{ }^{\circ} \mathrm{C}[\mathrm{J}]$. International Journal of Thermophysics, 2010, 31:1771-177. 